\title{
Prevalence of myopia among the medical students in western India vis-à-vis the east Asian epidemic
}

\author{
R. S. Sood ${ }^{1}$, A. Sood ${ }^{2}$ \\ ${ }^{\text {I}}$ (Department of Physiology, Padmashree Dr. DY Patil Medical College, Hospital \& Research Center, Pimpri, \\ Pune, India.) \\ ${ }^{2}$ (Family Physician, Pune, India.)
}

\begin{abstract}
The prevalence of myopia among students has reached epidemic proportions in east Asia. Indian data also suggests a high prevalence, especially in the southeast. We examined the trend locally, in 148 first MBBS students at a medical college in Pune, located in Maharashtra, a western state of India. We report a prevalence of $45 \%$ and compare it to that reported globally as well as from different regions of India. In the study population, we conclude, though myopia is quite prevalent, the east Asian trend of epidemic proportions is not yet evident. We emphasize timely institution of preventive measures to prevent an epidemic of myopia in India.
\end{abstract}

Keywords: Medical students, Myopia, Myopia epidemic, Prevalence

\section{INTRODUCTION}

Refractive error is the inability of the optical system to bring an image to a sharp focus on the retina. In myopia, the image falls short of retina, adversely affecting the distance vision. Like in many other diseases, both nature and nurture have been blamed [1]. In India, the prevalence of myopia is $7-11 \%$ in 15 year old and 35\% in adults [2]. Myopia increases the risk of cataract, glaucoma, retinal detachment, macular degeneration, choroidal neovascularization, visual impairment and blindness. It imposes substantial economic burden for the patients, immense societal costs and public health impact [3]. Recent reports suggest an Asian, especially east Asian trend of high prevalence of myopia among students, reaching 'epidemic' proportions [4-7]. Lately, MBBS students in India are also reported to have a high prevalence [8-10]. This study examined the prevalence of myopia among first MBBS students to confirm if this is true for this part of western India.

\section{MATERIAL AND METHODS}

\subsection{Study design}

This study was designed as a cross sectional descriptive study. The prevalence of myopia was calculated as proportion of the participants with myopia.

\subsection{Study population}

The sole inclusion criterion was: being a first MBBS student. The exclusion criteria included past history of glaucoma, diabetes mellitus, surgery or ocular injury. Institutional ethics committee clearance was obtained and 148 first MBBS students at a medical college in western Maharashtra volunteered to recruit. The mean (SD) age of the participants was 18.82 (1.34) years, age having been recorded as the number of completed years as on the nearer birthday. The sex distribution was 59\% (88/148) males and 41\% (60/148) females.

\subsection{Diagnosis of myopia}

A subject was classified as having myopia if the distance visual acuity (DVA) was worse than 20/20 in at least one of the eyes, which could be improved with the optical correction last prescribed or a pinhole instead.

\subsection{Data collection}

After informed consent, DVA was determined without the prescribed optical correction, if any, using a Snellen's test type. If it was worse than 20/20, the test was repeated with the optical correction last prescribed or with a pinhole, in case the optical correction was not yet prescribed.

DVA recorded was collapsed into categorical dichotomous scale, based on the presence or absence of myopia. Any improvement in the DVA with the optical correction last prescribed (or a pinhole), was recorded directly on a categorical dichotomous scale.

\subsection{Statistical analysis} participants.

Prevalence of myopia was calculated as a proportion of subjects detected to have myopia, per hundred 


\section{RESULTS}

Forty five percent (67/148) subjects were detected to have myopia.

\section{DISCUSSION}

The prevalence of $45 \%$ reported in this study is compared with that reported globally (TABLE 1) and other parts of India (TABLE 2). It was much lower than that reported from Taiwan, Singapore, China and Pakistan; slightly lower than that in Norway and Denmark; higher than that in Turkey and Poland [1, 4-6, 11$15]$.

Table 1: Prevalence of myopia in medical students: comparison with global data.

\begin{tabular}{|l|l|c|}
\hline Country & Study authors [Reference] & $\begin{array}{c}\text { Prevalence } \\
(\mathbf{\%})\end{array}$ \\
\hline Taiwan & Lin LL, et al [4]. & 93 \\
\hline Singapore & Woo WW, et al [5]. & 90 \\
\hline Singapore & Chow YC, et al [6]. & 82 \\
\hline China & Wu Y, et al [15]. & 71 \\
\hline Pakistan & Chaudhry R, et al [11]. & 58 \\
\hline Norway & Midelfart A, et al [12]. & 50 \\
\hline Denmark & Fledelius HC [13]. & 50 \\
\hline India & Present study. & $\mathbf{4 5}$ \\
\hline Turkey & Onal S, et al [1]. & 33 \\
\hline Poland & Mozolewska-Piotrowska K, et al [14]. & 32 \\
\hline
\end{tabular}

The prevalence of $45 \%$ in western Maharashtra that we report is much lower than that reported earlier from southeastern, western and central India [8-10].

Table 2: Prevalence of myopia in medical students: comparison with the Indian data.

\begin{tabular}{|l|l|c|}
\hline $\begin{array}{l}\text { Region of } \\
\text { India }\end{array}$ & Study authors [Reference\} & $\begin{array}{c}\text { Prevalence } \\
(\boldsymbol{\%})\end{array}$ \\
\hline Southeastern & Chalasani S, et al [8]. & 70 \\
\hline Western & Kathrotia RG, et al [9]. & 56 \\
\hline Central & Wakode NS, et al [10]. & 55 \\
\hline Western & Present study & $\mathbf{4 5}$ \\
\hline
\end{tabular}

Medical students have high prevalence of myopia, reaching epidemic proportions, in the east Asia [46]. Even the school children in this region have developed very high prevalence of epidemic proportions [7]. Researchers point to a recent trend of high level of curricular near work indulged by the children in this region. Medical students too, have to indulge in a lot of curricular near work, probably predisposing them to development of myopia. Furthermore, excessive near work indulged by students is a known risk factor for myopia [16]. Therefore, it is possible that academic competition led to selection of more myopes for medical education.

Excessive near work as a risk factor for myopia is underlined by the findings of the following studies. As per a study published in 1969, the then recently acculturated Eskimos showed a very large difference in prevalence between older subjects (1.5\%), who had little or no schooling vis-à-vis the younger subjects (51\%), who had compulsory schooling [17]. The high prevalence of myopia in these younger Eskimos was thought to be due to the then recently introduced excessive near work of reading [17]. Optometry students, who perform extensive near work, were detected to have been at risk of developing myopia. Their myopic progression was related to the high demands for near work and could be slowed in vacations while near work decreased [18].

It has also been suggested that increasing westernization, particularly the availability of store-bought food that was high in sugars and carbohydrate, may have been associated with the rapid increase of myopia noted in the then recently acculturated Eskimos [17].

\section{CONCLUSION}

Myopia is quite prevalent in the study population but the east Asian trend of epidemic proportions has not yet arrived. Prevalence is also much lower than that reported earlier among the medical students from different regions of India. The trend needs to be substantiated with larger studies on the various groups at risk. Absence of dropout is an advantage of this study. We recognize lack of auto-refraction as a limitation. This 
study points to the window of opportunity still available to institute possible preventive measures against myopia before it assumes epidemic proportions in our population.

\section{REFERENCES}

[1] S. Onal, E. Toker, Z. Akingol, G. Arslan, S. Ertan, C. Turan and O. Kaplan, Refractive errors of medical students in Turkey: one year follow-up of refraction and biometry, Optometry and Vision Science, 84(3), 2007, 175-180.

[2] C.W. Pan, D. Ramamurthy and S.M. Saw, Worldwide prevalence and risk factors for myopia, Ophthalmic \& Physiological Optics, 32(1), 2012, 3-16

[3] Y.F. Zheng, C.W Pan, J. Chay, T.Y. Wong, E. Finkelstein and S.M. Saw, The economic cost of myopia in adults aged over 40 years in Singapore, Investigative Ophthalmology and Visual Science, 54(12), 2013, 7532-7537.

[4] L.L. Lin , Y.F. Shih, Y.C. Lee, P.T. Hung and P.K. Hou, Changes in ocular refraction and its components among medical studentsa 5-year longitudinal study, Optometry and Vision Science, 73(7), 1996, 495-498.

[5] W.W. Woo, K.A. Lim, H. Yang, X.Y. Lim, F. Liew, Y.S. Lee and S.M. Saw, Refractive errors in medical students in Singapore, Singapore Medical Journal, 45(10), 2004, 470-474.

[6] Y.C. Chow, B. Dhillon, P.T. Chew and S.J. Chew, Refractive errors in Singapore medical students, Singapore Medical Journal, 31(5), 1990, 472-473.

[7] L.L. Lin, Y.F. Shih, C.B. Tsai, C.J. Chen, L.A. Lee, P.T. Hung and P.K. Hou, Epidemiologic study of ocular refraction among schoolchildren in Taiwan in 1995. Optometry and Vision Science, 76(5), 1999, 275-281.

[8] S. Chalasani, V.K. Jampala and P. Nayak, Myopia among Medical Students-A Cross Sectional Study in A South Indian Medical College, Al Ameen Journal of Medical Sciences, 5(3), 2012, 233-242.

[9] R.G. Kathrotia, A.G. Dave, S.T. Dabhoiwala, N.D. Patel, P.V. Rao and E.R. Oommen, Prevalence and progression of refractive errors among medical students, Indian Journal of Physiology and Pharmacology, 56(3), 2012, 284 -287.

[10] N.S. Wakode, S.L. Wakode and D.D. Ksheersagar, Risk Factors for Myopia in Medical Students, International Journal of Recent Trends in Science and Technology, 8(1), 2013, 09-11.

[11] R. Chaudhry, H. Ali and N.H. Sheikh, Frequency and underlying factors of myopia among medical students, Biomedica, 27(2), $2011,154-160$

[12] A. Midelfart, B. Aamo, K.A. Sjøhaug and B.E. Dysthe, Myopia among medical students in Norway, Acta Ophthalmologica, 70(3), $1992,317-322$

[13] H.C. Fledelius, Myopia profile in Copenhagen medical students 1996-98. Refractive stability over a century is suggested, Acta Ophthalmologica Scandinavica, 78(5), 2000, 501-505.

[14] K. Mozolewska-Piotrowska, J. Stepniewska and J. Nawrocka, Frequency and incidence of myopia among medical students, Klinika Oczna, 107(7-9), 2005, 468-470.

[15] Y. Wu, H. Yi, W. Liu, H. Jia, Y. Eshita, S. Wang, P. Qin and J. Sun, Risk factors for myopia in Inner Mongolia medical students in China, Open Journal of Epidemiology, 2 (4), 2012, 83-89.

[16] S.M. Saw, W.H. Chua, C.Y. Hong, H.M. Wu, W.Y. Chan, K.S. Chia, R.A. Stone and D. Tan, Nearwork in early-onset myopia, Investigative Ophthalmology and Visual Science, 43(2), 2002, 332-339.

[17] F.A. Young, G.A. Leary, W.R. Baldwin, D,C. West, R.A. Box, E. Harris and C. Johnson, The transmission of refractive errors within eskimo families, American Journal of Optometry and Archives of American Academy of Optometry, 46(9), 1969 , 676-685.

[18] B.C. Jiang, S. Schatz and K. Seger, Myopic progression and dark focus variation in optometric students during the first academic year, Clinical and Experimental Optometry, 88(3), 2005, 153-159. 